RESEARCH ETHICS

\title{
Medical decision making in scarcity situations
}

\author{
J J M van Delden, A M Vrakking, A van der Heide, P J van der Maas
}

J Med Ethics 2004;30:207-211. doi: 10.1136/jme.2003.003681

The issue of the allocation of resources in health care is here to stay. The goal of this study was to explore the views of physicians on several topics that have arisen in the debate on the allocation of scarce resources and to compare these with the views of policy makers. We asked physicians (oncologists, cardiologists, and nursing home physicians) and policy makers to participate in an interview about their practices and opinions concerning factors playing a role in decision making for patients in different age groups. Both physicians and policy makers recognised allocation decisions as part of their reality. One of the strong general opinions of both physicians and policy makers was the rejection of age discrimination. Making allocation decisions as such seemed to be regarded as a foreign entity to the practice of medicine. In spite of the reluctance to make allocation decisions, physicians sometimes do. This would seem to be only acceptable if it is justified in terms of the best interests of the patient from whom treatment is withheld.

See end of article for authors' affiliations

Correspondence to: Johannes J M van Delden; ijmvandelden@jc.azu.nl

Revised version received 23 April 2003

Accepted for publication 2 June 2003
M system. Doctors and nurses respond to the needs of their patients, whether these are articulated or not. The habit of responding to the cry "is there a doctor around?" is one of the backbones of medicine, but it inevitably also has its drawbacks. One of them is that needs tend to be endless, whereas the funds allocated to the healthcare system, be it $8 \%$ of the gross national product (as in the Netherlands) or 13\% of it (as in the US), ${ }^{1}$ are not. The fact that healthcare needs are indeed endless is not only derived from ever more demanding patients who seem to value their health above all other goods, but is in a sense the result of medicine's own success. Preventing an early death not only results in longer life but often also in a prolonged need for medical support. ${ }^{2}$ The success of medical treatment of myocardial infarction is a case in point. Those who survive the acute heart attack have an increased risk for developing new cardiac diseases and many of them will therefore need continued medical attention. The simple truth is that effective health care tends to become more expensive. Allocation of scarce resources, therefore, will remain a problem of modern health care.

This allocation problem has triggered (among other things) a lengthy debate among ethicists on the justified (or unjustified) role of nonmedical criteria in decision making. One focus in edicine by definition is a need driven this debate certainly has been on age. Daniels for example pointed to the fact that limiting health care at a certain age need not be regarded as age discrimination because we all hope to live to that age. By taking an intragenerational view on this, instead of construing it as an intergenerational conflict, the prudent planner would certainly be able to accept some form of age based rationing. ${ }^{3}$ Callahan also argued for this, but on totally different grounds. His theory was based on a detailed account of what it means to be old and what goals should be pursued at old age and what not. According to Callahan, coming to terms with the fact that life is finite should be a major issue in this phase of life, not striving for immortality. After a certain age, therefore, life sustaining treatments should no longer be applied. ${ }^{4}$ Harris basically rejects age based rationing because what counts most, according to him, is any person's wish to prolong his or her life. He admits, however, that death at young age is a tragedy, while a misfortune at old age: at least the latter has had his or her fair innings. ${ }^{5}$ In the Netherlands, government committees have tried to formulate policies on the basis of some of these views, but their advice was never really implemented. ${ }^{67}$

Apart from the discussion about the tenability of these arguments, there also is a discussion about the locus of decision making: should it be on the macro level, on the micro level, or could some of the responsibility be shared between government and profession?

The present study was based on three epidemiological observations. Firstly, the percentage of elderly in the population will rise. It is expected that by the year 2035 about $25 \%$ of the Dutch population will be over 65 years of age. ${ }^{8}$ Secondly, more non-treatment decisions are being taken. ${ }^{9}$ Thirdly, it is expected that the costs of health care will rise. The latter is expected not only because of the demographical trend, but also because the average age specific demand for health care will rise. This is so, because medical interventions tend to become less dangerous and can therefore be applied at an increasingly old age and also because the consumer of the future health care is expected to be more demanding. The goal of this study was to explore the views of physicians on several topics that have arisen in the debate on the allocation of scarce resources with a particular focus on the role of age, and to compare these with the views of policy makers.

\section{METHODS}

We asked oncologists, cardiologists, and nursing home physicians in the southwest region of the Netherlands (Utrecht, Zuid-Holland, southern 
part of Noord-Holland, western part of Noord-Brabant) to participate in an interview about their practices and opinions concerning factors playing a role in their medical decision making for patients in different age groups. These specialties were selected because elderly patients form a relevant proportion of their patient population and they generate a relevant part of the costs of health care. The respondents were selected by drawing a systematic sample from the respective professional register, which were ordered by postal code. All physicians had to have been registered in their specialty for at least 2 years. Respondents were visited by specially trained interviewers.

We asked policymakers from insurance companies (directors, senior staff, and medical advisors), governmental bodies (members of parliament, senior civil servants from the ministry of health, or from advisory councils), and healthcare institutions (general hospitals, academic hospitals, and nursing homes) to participate in an interview by telephone. We included respondents from insurance companies because they play a key role in the Dutch health care system collecting premium income, financing the system, and monitoring the quality, costs, and effectiveness of care services. All respondents were selected by the "snowball method". This meant that we asked key persons to advise us which key players in top positions we should ask to participate.

Physicians at interview were asked to describe their practices concerning the treatment of seriously ill patients, discussing both real cases and hypothetical ones. Policymakers were asked what in their opinion should play a role in these practices. The questionnaire also included 14 statements, which were identical for physicians and policy makers, and the answers to these statements are reported here. They were based on a literature study of the main ethical lines of reasoning concerning allocation decisions in health care. In the statements, both thoughts about the locus of decision making as well as ideas about proper arguments were studied. The statements were introduced in a way that explicitly referred to issues concerning the allocation of scarce resources. They were presented to the respondents in a random order. Respondents could respond to these statements on a five point Likert scale from "totally agree" to "totally disagree".

\section{ANALYSIS}

Differences were calculated with the Mann-Whitney test between physicians from the different specialties and between all physicians and policy makers for a three point scale. That is, "totally agree" and "more agree than disagree" was regarded as one category, as were "totally disagree" and "more disagree than agree". Only percentage agreement is shown. Answers were considered significantly different if the $\mathrm{p}$ value was equal to or less than 0.05. A principal components analysis was performed on the opinions of the respondents, but this failed to reveal any relationships. The analysis on 14 opinions resulted in a value of 0.17 of the first component, which is very low, and means that the opinions were virtually uncorrelated to each other.

\section{RESULTS}

The response rates were $42 \%$ for the cardiologists, $59 \%$ for the oncologists, and $91 \%$ for the nursing home physicians (table 1). Mean age of the physician respondents and the distribution of their sex did not deviate from those of all physicians in these specialities in the Netherlands. The mean number of beds in the institution where the respondents work indicates that they represent rather large hospitals (oncologists and cardiologists) or nursing homes (nursing home physicians).
Table 1 Response rates and characteristics of the respondents

\begin{tabular}{|c|c|c|c|c|}
\hline & $\begin{array}{l}\text { Oncologists } \\
(\mathrm{n}=30)\end{array}$ & $\begin{array}{l}\text { Nursing } \\
\text { home } \\
\text { physicians } \\
\text { (n=29) }\end{array}$ & $\begin{array}{l}\text { Cardiologists } \\
(n=21)\end{array}$ & $\begin{array}{l}\text { Policy } \\
\text { makers } \\
(n=29)\end{array}$ \\
\hline Response (\%) & 59 & 91 & 42 & 76 \\
\hline $\begin{array}{l}\text { Age (mean, } \\
\text { years) }\end{array}$ & 49 & 44 & 48 & Unknown \\
\hline $\begin{array}{l}\text { Women (\%) } \\
\text { Estimated } \\
\text { proportion of } \\
\text { patients aged }\end{array}$ & 23 & 52 & 5 & 24 \\
\hline $\begin{array}{l}>65 \text { years (\%) } \\
\text { Estimated } \\
\text { proportion of } \\
\text { patients aged }\end{array}$ & 41 & 89 & 64 & $\mathrm{Na}$ \\
\hline $\begin{array}{l}>80 \text { years }(\%) \\
\text { Hospital beds }\end{array}$ & 9 & 65 & 17 & $\mathrm{Na}$ \\
\hline (mean) & 572 & 181 & 566 & $\mathrm{Na}$ \\
\hline
\end{tabular}

To be able to speak with 29 policy makers we had to contact 38 persons. If a policy maker was not able to participate in the interview we asked him to identify another key person in his field. Nine contacts did not result in an interview, for several reasons: they were too busy, or thought they were not the right person for the interview; one could not be reached; another one had changed jobs. The respondents consisted of 10 key persons from insurance companies, eight from governmental bodies and 11 from healthcare institutions (both hospitals and nursing homes). The total number of respondents interviewed was 109: 80 physicians and 29 policy makers.

The answers to the 14 statements are described in tables 2, 3 , and 4 . Table 2 describes the answers to the statements concerning the use of some selection criteria. Both physicians and policy makers reject age discrimination as such (second statement, table 2). Shortage of staff, with scarcity of beds as a result, is still almost unanimously rejected as grounds for age selection, but half of physicians want to use expensive life-prolonging treatments primarily to save the life of people younger than 75 years. In case of scarcity of organs for transplantation two thirds felt it was acceptable to select patients on their age. The percentage of agreement among policy makers for these statements also grew in this order, but remained less than among physicians.

On three statements the policy makers significantly disagreed with the physicians. They less frequently thought that under treatment of older patients occurs. Moreover, they were more prepared to use expensive life-prolonging treatment for elder patients, and were less prepared to allow physicians to use social criteria.

There is a significant difference between specialties about whether expensive life-prolonging treatments should be primarily used to prevent the death of people $<75$ years of age. Almost two thirds of oncologists agreed with this statement, while two thirds of the nursing home physicians disagreed. The latter responded in the same way as the policy makers.

Table 3 demonstrates the locus of decision making. Physicians primarily look to the government for making allocation decisions. According to $91 \%$ of the physicians, their primary concern should be the interests of their patients. They accept that their decisions influence the distribution of means and are willing to take this into account. Guidelines on making individual treatment choices in this area was welcomed by $56 \%$, and the same percentage of physicians do not think that restrictions enforced by the government 
Table 2 Percentage of agreement with statements concerning the use of selection criteria

\begin{tabular}{|c|c|c|c|c|c|}
\hline \multirow[b]{2}{*}{ Statement } & \multicolumn{5}{|c|}{ Agreement with statement (\%) } \\
\hline & $\begin{array}{l}\text { Oncology } \\
(n=30)\end{array}$ & $\begin{array}{l}\text { Nursing } \\
\text { home } \\
(n=29)\end{array}$ & $\begin{array}{l}\text { Cardiology } \\
(n=21)\end{array}$ & $\begin{array}{l}\text { Physicians } \\
\text { total } \\
(\mathrm{n}=80)\end{array}$ & $\begin{array}{l}\text { Policy } \\
\text { makers } \\
\text { ( }=29)\end{array}$ \\
\hline $\begin{array}{l}\text { In older patients under treatment occurs mor } \\
\text { often than in younger patients }\left(p=0.03^{*}\right) \\
\text { Older patients shouldn't be victims of scarcit } \\
\text { in health care more often than younger }\end{array}$ & ty & 62 & 75 & 70 & 45 \\
\hline $\begin{array}{l}\text { patients } \\
\text { In case of scarcity of beds as a consequence } \\
\text { of a shortage of staff, it is acceptable that } \\
\text { patients are selected by their age upon }\end{array}$ & $\mathrm{ce}^{93}$ & 86 & 76 & 86 & 83 \\
\hline $\begin{array}{l}\text { admission } \\
\text { Expensive life prolonging treatments should } \\
\text { be used primarily to prevent the death of } \\
\text { people younger than } 75 \text { years of age }\end{array}$ & 3 & 7 & 10 & 6 & 7 \\
\hline $\begin{array}{l}\left(p=0.02^{*}, p=0.002+\right) \\
\text { In case of scarcity of organs for } \\
\text { transplantation it is acceptable that patients }\end{array}$ & 63 & 35 & 52 & 50 & 28 \\
\hline $\begin{array}{l}\text { are selected on their age } \\
\text { A good physician takes the functions that a } \\
\text { patient fulfils in family and society into } \\
\text { account in important medical decisions. } \\
\left(p=0.009^{*}\right)\end{array}$ & 53 & 62 & 67 & 68 & 48 \\
\hline
\end{tabular}

interfere with good medical practice. The policy makers mainly agreed with physicians about the statements.

In table 4 three important ethical positions concerning allocation decisions are described. The first statement reflects Callahan's idea about the natural life span. The second describes the fair innings argument put forward by John Harris. The last statement formulates Norman Daniels' distributive rule, which a prudent planner would have chosen. A large majority of physicians agree with the first statement, whereas three quarters of them reject the other two. Policy makers gave broadly similar answers.

\section{DISCUSSION}

Both physicians and policy makers recognise allocation decisions are part of the current medical reality. They believe that these types of decisions occur and have opinions about them. One of the strong general opinions of both physicians and policy makers is the rejection of age discrimination. This general opinion is qualified in specific circumstances. Shortage of staff and the resulting scarcity of beds is still almost unanimously rejected as grounds for age selection but half of physicians agree that expensive life prolonging treatments should be primarily used to save the life of people $<75$ years. In case of scarcity of organs for transplantation, two thirds of respondents find it acceptable to select patients based on their age. The percentage of agreement among policy makers also grew for this sequence of justifications for selection according to age, but remained less than among physicians. One explanation could be that physicians tend to also use age as a proxy for the chance of medical success. We

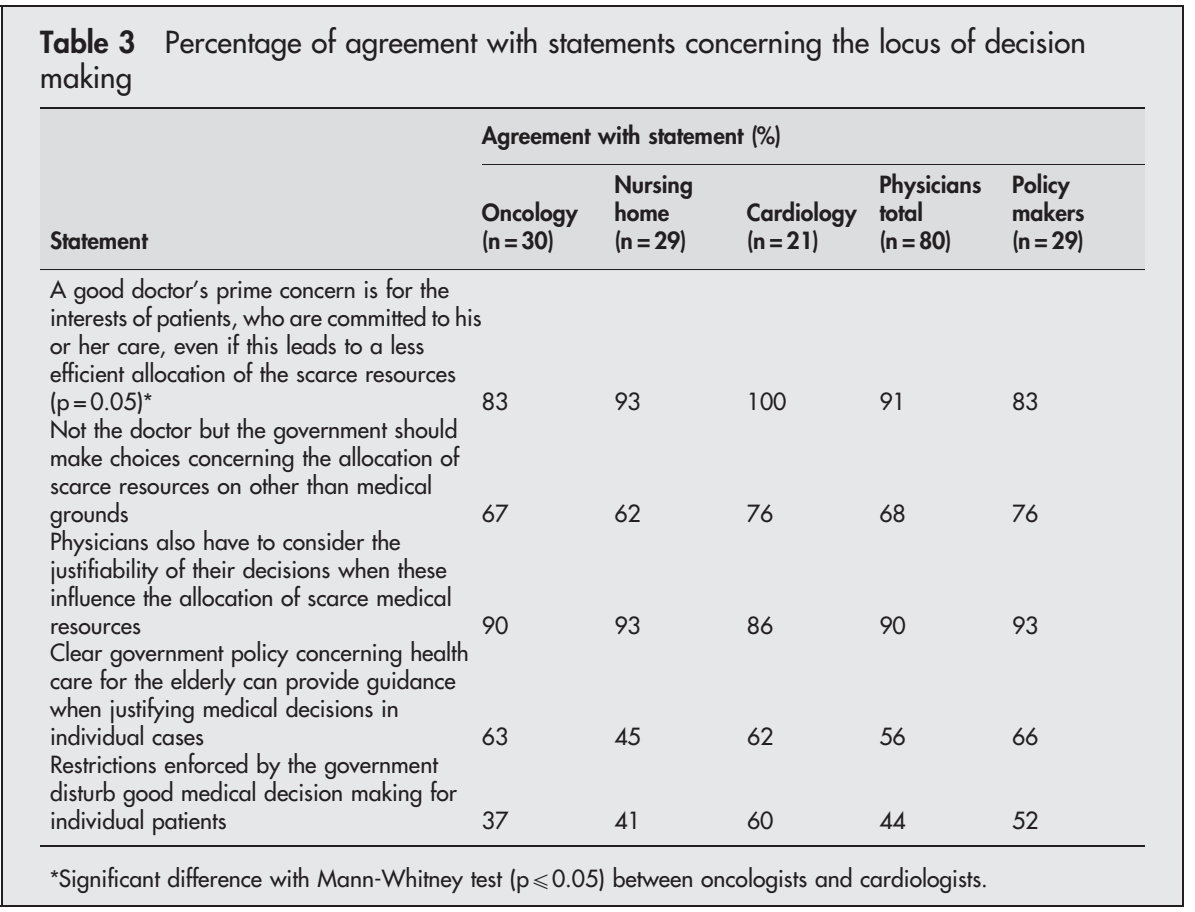




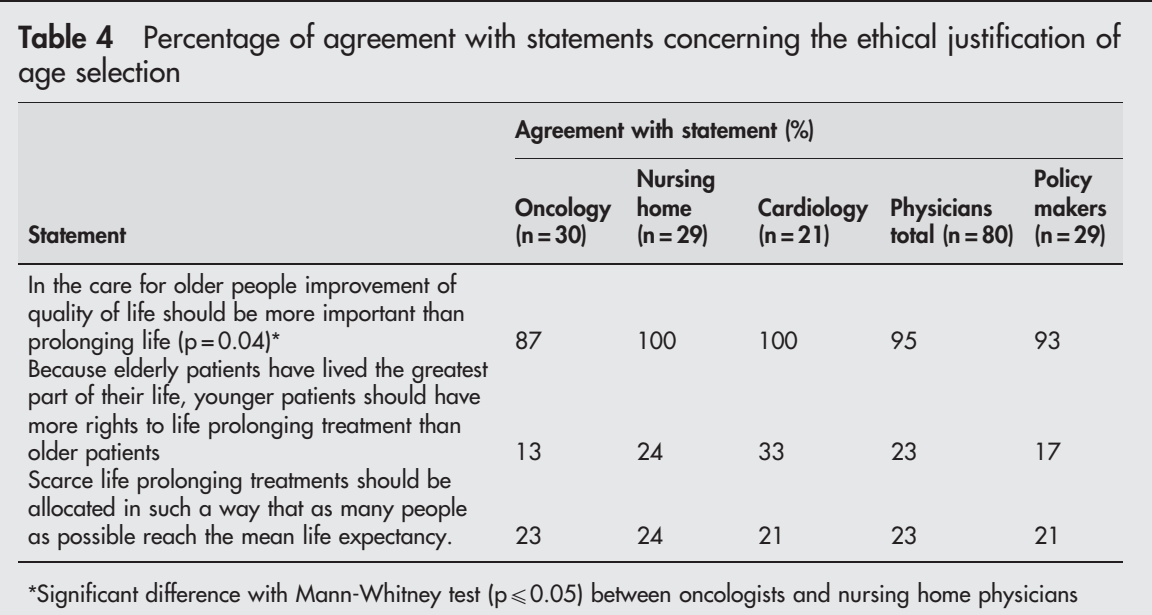

do not think, however, that the agreement with these statements among physicians can be explained entirely by the fact that they might have read them as containing only medical information as the context and the wording of the statements underlined the non-medical content of the criteria. Moreover, the fact that $61 \%$ of physicians accept social conditions as valid criteria for allocation decisions shows that in certain circumstances they accept criteria that are not strictly medical.

Physicians tend to primarily look to the government for making allocation decisions. In their view, their primary concern should be the interests of their patients. They accept that their decisions influence the distribution of means and are willing to take this into account, but choosing between patients is not their job. This is consistent with their acceptance of guidelines to make individual treatment choices and even of restrictions enforced by the government. Interestingly enough, policy makers agree with them in all these statements. They clearly accept a role for physicians who give priority to the interests of their patients, not to those of society at large. The position of the respondents could be summarised as follows: the main virtue of physicians is compassion not justice. We agree.

We also tried to capture the main thoughts of three important ethical positions in the statements. The fair innings and intragenerational distribution arguments of health care were rejected. It is interesting that the latter idea has as little support among policy makers as among physicians. In a recent report of the scientific council for government policy, Daniels's ideas were explicitly quoted as a good way of distributing scarce resources in health care. ${ }^{7}$ This theory applies a Rawlsian line of thinking involving a veil of ignorance and a prudent planner who is stripped of knowledge about his future position and health status. It is therefore by nature rather theoretical, which could explain its unattractiveness among physicians but less so among policy makers.

Our study shows that Callahan's theory is accepted as the best theory both by physicians and by policy makers. We found an overwhelming support for the idea that in old age improving quality of life should have priority over prolonging life. An important feature of this statement is that nontreatment is suggested to be beneficial for the patient. It would seem, therefore, that making choices between patients may be acceptable if this is justified in terms of the interests of the patient from whom treatment is withheld. In such cases it appears to be accepted that some deaths that could have been prevented are allowed to happen.

Of course this study has its limits. The findings of this study cannot be generalised for other specialties and the number of respondents was limited. Moreover, it is impossible to do justice to a complete ethical theory and reduce it to one statement at the same time. Even if we managed to capture the main thoughts of such theory in one line, the result may have been rather difficult for the respondents to interpret. Nevertheless, we feel that the findings reflect the normative beliefs of relevant stakeholders in the scarcity debate.

What practical wisdom have we found? We think two key messages emerge. Firstly, making allocation decisions is regarded as a foreign entity in the practice of medicine. The interesting thing is that this not only is the view held by physicians but also by policy makers. Related to this view is the idea that the government should take responsibility and make the allocation decisions. Guidelines appear to be an accepted method for doing so.

Secondly, in spite of the reluctance to make allocation decisions, physicians sometimes do. Based on the large acceptance of the statement reflecting Callahan's theory, the main idea seems to be that this is only acceptable if justified in terms of the interests of the patient from whom treatment is withheld. This would seem to be related to a view that emphasises a different understanding of old age. If persons would be prepared to accept that life is finite and some form of decline is part of life, this would influence the sort of demand these persons put on health care. In this view both physicians and patients are invited to realise that the fact that humans are mortal is fundamental to everything we value and treasure. ${ }^{10}$

\section{Authors' affiliations}

A M Vrakking, A van der Heide, P J van der Maas, Department of Public Health, Erasmus MC, Rotterdam, Netherlands

J J M van Delden, Julius Center for Health Sciences, University Medical Centre, Utrecht, Netherlands

This study was supported by a grant from the Dutch Organisation for Scientific Research.

At the time of the study JMM van Delden was at the Centre for Bioethics and Health Law, Utrecht University, Netherlands.

\section{REFERENCES}

1 Organisation for Economic Co-operation and Development. Health data 2002. Paris, France: OECD, 2002.

2 Bonneux L, Barendregt JJ, Nusselder WJ, et al. Preventing fatal diseases increases healthcare costs: cause elimination life table approach. BMJ 1998;316:26-9.

3 Daniels N. Am I my parents' keeper? New York: New York University Press, 1988.

4 Callahan D. Terminating treatment: age as a standard. Hastings Cent Rep 1987; 17:21-5.

5 Harris J. The value of life. London: Routledge, 1985

6 Commissie Keuzen in de zorg (commissie Dunning). Kiezen of delen. Den Haag: staatsdrukkerii, 1991. 
7 Wetenschappelijke Raad voor het Regeringsbeleid (WRR). Generatiebewust beleid. Den Haag: WRR, 1998.

8 Van der Maas PJ. Vergriizing, Volksgezondheid en de vraag naar zorg. In: Delden JJM van, Hertogh CMPM, Manschot HAM, eds. Morele problemen in de ouderenzorg. Assen: Van Gorcum, 1999.
9 Groenewoud JH, van der Heide A, Kester JGC et al. A nationwide study of decisions to forego life-prolonging treatment in Dutch Medical practice. Arch Intern Med 2000; 160:357-63.

10 Nussbaum MC. Love's knowledge. Essays on philosophy and literature. Oxford: Oxford University Press, 1990. 